\title{
Optimum Spacings of Longitudinal Convective Fin Arrays
}

\author{
Rong-Hua Yeh \\ Professor, Department of Marine Engineering and Technology, National Taiwan Ocean University, Keelung, Taiwan, \\ R.O.C. \\ Shih-Pin Liaw \\ Professor, Department of Mechanical and Marine Engineering, National Taiwan Ocean University, Keelung, Taiwan, \\ R.O.C. \\ Ming Chang \\ Graduate Student, Institue ofMaritime Technology, National Taiwan Ocean Universiry, Keelung, Taiwan, W.O.C.
}

Follow this and additional works at: https://jmstt.ntou.edu.tw/journal

Part of the Engineering Commons

\section{Recommended Citation}

Yeh, Rong-Hua; Liaw, Shih-Pin; and Chang, Ming (1997) "Optimum Spacings of Longitudinal Convective Fin Arrays," Journal of Marine Science and Technology. Vol. 5: Iss. 1, Article 6.

DOI: $10.51400 / 2709-6998.2537$

Available at: https://jmstt.ntou.edu.tw/journal/vol5/iss1/6

This Research Article is brought to you for free and open access by Journal of Marine Science and Technology. It has been accepted for inclusion in Journal of Marine Science and Technology by an authorized editor of Journal of Marine Science and Technology. 


\title{
OPTIMUM SPACINGS OF LONGITUDINAL CONVECTIVE FIN ARRAYS
}

\author{
Rong-Hua Yeh*, Shih-Pin Liaw** and Ming Chang***
}

Keywords: optimum spacing, fin array, forced convection.

\section{ABSTRACT}

This paper deals with the optimum spacings of longitudinal fin arrays in forced convection theoretically. Four different fins in arrays such as rectangular, convex-parabolic, triangular, and concave-parabolic fins are taken into consideration in the analysis. The aspect ratio, interfin spacing, and heat transfer characteristics of the optimized fin arrays are investigated with given geometry of base plate, total fin volume, and transverse Biot number. A comparison in the total heat duties and overall surface efficiencies of the four different arrays is also made. All the results are presented in dimensionless forms for the convenience of parametric study and design analysis.

\section{INTRODUCTION}

Heat transfer from a system can be increased by extending the surface area through the addition of fins. It is of great importance in various industrial applications such as aerospace, air-conditioning, electronic components, and automobile radiators. Apparently, in most of these applications, the weight is a primary consideration in the heat exchanger design.

A comprehensive review of fin technology was presented by Kraus [1] for over six decades. In addition to the fundamentals of heat transfer characteristics of fins, Kern and Kraus [2] gave a thorough treatment for the optimum design of convecting fins. Lately, to improve the design of extended surfaces, a lot of works [3-7] have been done in the optimization

Paper Received February, 1997. Revised May, 1997. Accepted May, 1997. Author for Correspondence: Rong-Hua Yeh.

*Professor, Department of Marine Engineering and Technology, National Taiwan Ocean University, Keelung, Taiwan, R.O.C.

**Professor, Department of Mechanical and Marine Engineering, National Taiwan Ocean University, Keelung, Taiwan, R.O.C.

***Graduate Student, Institue of Maritime Technology, National Taiwan Ocean University, Keelung, Taiwan, W.O.C. of a single fin by achieving a specified heat duty with the minimum materials for temperature dependent thermal parameters.

All the foregoing methods are essentially applicable for the case of a single fin. In actual practice, however, an engineer rarely comes across a single fin. Besides, the recent concern over the thermal efficiency of energy conversion equipment have furthermore focused on the optimization of free and forced convection fin arrays. In the design of fin arrays of heat exchangers in vehicles and vessels, it demands that the requisite thermal load be dissipated with minimum volume and weight. This requirement can be met by choosing fin dimensions which maximize heat dissipation per fin volume. Several studies of free convection from multiple surfaces can be found in literature [8-11]. Due to the nonlinear characteristics of this problem, most of the works were investigated experimentally. In forced convection, Dhar and Arora [12] obtained the optimum fin profile and concluded that the use of individually optimum profile fins did not necessarily result in the optimum finned surfaces. The least material of convectively cooled arrays of longitudinal, rectangular fins were theoretically proposed by Bar-Cohen and Jelinek [13]. In their work, it is pointed out that the aspect ratio of the array optimum fin is found to be only marginally thinner than implied by the conventional single optimum fin.

In this study, to maximize the total heat dissipation in forced convection, the optimum aspect ratio and spacing between fins are obtained for a given height and width of base plate, total fin volume, fin thickness at root. Various fin profiles including rectangular, convex parabolic, triangular, and concave parabolic ones are employed and analyzed in the fin arrays. A least-material-fin array is found by comparing the total heat dissipation of the four different finned and unfinned surfaces. The optimum heat transfer characteristics as well as efficiency of the fin assembly are investigated. 


\section{ANALYSIS}

Figure 1 shows the terminology for an array with longitudinal rectangular fins. Although only the rectangular fin is shown in Fig. 1a, many configurations of fins displayed in Fig. 1b can be established on a vertical surface. The general fin profile function is expressed as

$$
f(x)=\frac{b}{2}\left(\frac{x}{l}\right)^{n},
$$

where $b$ and $l$ stand for the thickness at fin base and height of the fin. In the above equation, the profile index, $n$, represents rectangular fin for $n=0$, convex parabolic fin for $n=0.5$, triangular fin for $n=1$, and concave parabolic fin for $n=2$ respectively.

Applying the Gardner-Murray assumptions $[14,15]$, the one-dimensional steady state heat conduction equation governing a longitudinal fin can be written as

$$
\frac{d}{d x}\left(x^{n} \frac{d \theta}{d x}\right)-\frac{2 h l^{n}}{k b} \theta=0 .
$$

In the above equation, $k$ is the thermal conductivity of the fin, $h$ is a heat transfer coefficient and $\theta$ is the temperature difference between the fin surface and the ambient fluid. With a uniform temperature distribution at the fin base and an appropriate boundary condition at fin tip, Eq. (2) can be readily solved to obtain the heat dissipation of a single fin. The total heat transfer rate of a fin array are calculated by summing the area occupied by the fins and the interfin spacing area. An array with least material can then be found by assuming that the primary area is isothermal. The validity of this assumption is expected to improve as the fin spacing decreases and the thermal conductivity as well as thickness of the fin support plate increases [9].

\section{Optimum Array with Rectangular Fins (n=0)}

The heat transfer rate of a rectangular fin with negligible heat loss from tip can be found in [2] and is written as

$$
Q_{f}=\theta_{b} H(2 k b h)^{1 / 2} \tanh \left[\left(\frac{2 h}{k b}\right)^{1 / 2} l\right] \text {. }
$$

With some substitution in Eq. (3) and the addition of the heat dissipation from spacings of fins, the heat duty of an array is calculated as

$$
\begin{aligned}
Q= & \frac{W H \theta_{b}}{b+s}\left\{h s+(2 k b h)^{1 / 2} \tanh \left[\left(\frac{2 h}{k b}\right)^{1 / 2}\right.\right. \\
& \left.\left.\frac{V(b+s)}{W H b}\right]\right\},
\end{aligned}
$$
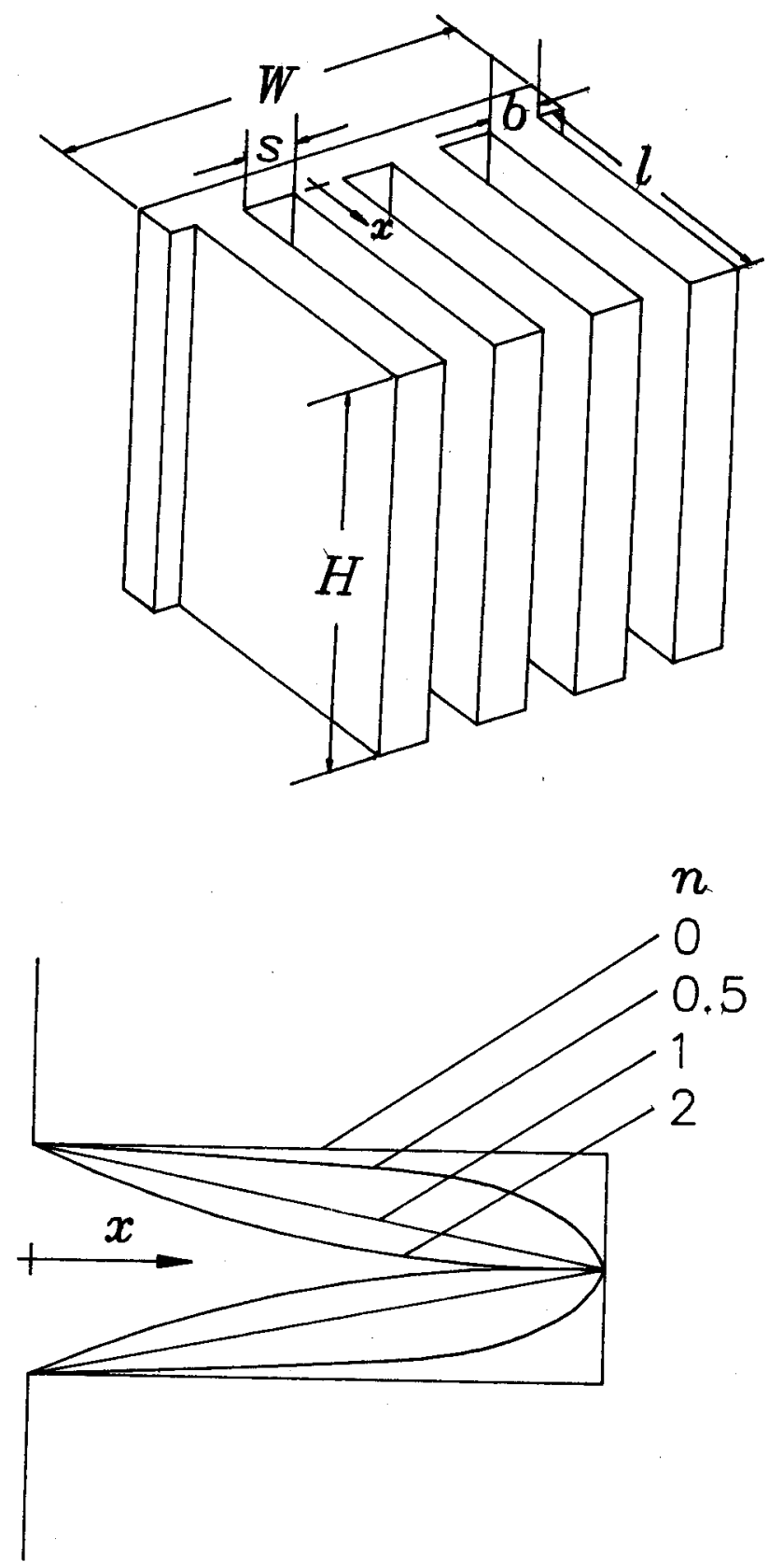

Fig. 1. (a) Geometric definition of a longitudinal fin array.(b) Various fin profiles used in this study.

where $V$ is the total volume of fins and $W, H, b, s$ are given in Fig. 1. If the number of fins is large, the number of fins can be assumed to be the same as the number of inter-fin spacing which equals $W /(b+s)$. To find the maximum heat dissipation of an array at fixed $V$ and $b$, it is possible to differentiate Eq. (4) with respect to $s$ and set the derivative identical to zero. It yields 


$$
\begin{gathered}
\left(\frac{B_{i}}{2}\right)^{1 / 2}+\left(2 B_{i}\right)^{1 / 2} \beta \operatorname{Sech}^{2}\left[\left(2 B_{i}\right)^{1 / 2} \beta\right] \\
-\tanh \left[\left(2 B_{i}\right)^{1 / 2} \beta\right]=0,
\end{gathered}
$$

where $B_{i}$ is a transverse Biot number and is defined as $h b / \mathrm{k}$ and $\beta$ represents $V(b+s) /\left(W H b^{2}\right)$. The optimum $\beta$ may be directly evaluated from Eq. (5) for a given $B_{i}$. Furthermore, the optimum aspect ratio and dimensionless spacing of the fin array are obtained as

$$
\left(\frac{l}{b}\right)_{\text {opt }}=\beta
$$

and

$$
\left(\frac{s}{b}\right)_{\text {opt }}=\gamma \beta-1,
$$

where $\gamma$ includes the geometric factors of the base plate of the fin array and is equal to $W H b / V$. The dimensionless heat duty of the optimum fin assembly are calculated as

$$
Q^{*}=\left\{(\not \beta-1)\left(\frac{B_{i}}{2}\right)^{1 / 2}+\tanh \left[\left(2 B_{i}\right)^{1 / 2} \beta\right]\right\} /(\gamma \beta) .
$$

Fin efficiency, $\eta$, is defined as the ratio of total heat transfer of a fin to the ideal heat transfer of isothermal fin at the base plate temperature. It is shown as

$$
\eta=\frac{\tanh \left[\left(2 B_{i}\right)^{1 / 2} \beta\right]}{\left(2 B_{i}\right)^{1 / 2} \beta} .
$$

In contrast to the fin efficiency $\eta$, which characterizes the performance of a single fin, the overall surface efficiency $\in[16]$ characterizes an array of fins and the base surface to which they are attached. For a rectangular-fin array, one obtains

$$
\epsilon=1-\frac{2(\beta+1)(1-\eta)}{\beta(\gamma+2)+1}
$$

\section{Optimum Array with Convex Parabolic Fins $(\mathbf{n}=0.5)$}

From [2], the heat transfer rate of this fin is calculated as

$$
Q_{f}=\theta_{b} H(2 k b h)^{1 / 2} \frac{I_{2 / 3}(2 m l)}{I_{-1 / 3}(2 m l)} .
$$

If the array base plate surface is attached with convex parabolic fins which are insulated at tips, the total heat dissipation from fin array becomes

$$
Q=\frac{W H \theta_{b}}{b+s}\left\{h s+(2 k b h)^{1 / 2} \frac{I_{2 / 3}(2 m l)}{I_{-1 / 3}(2 m l)}\right\},
$$

where

$$
m l=\left(\frac{2 h}{k b}\right)^{1 / 2} \frac{V(b+s)}{W H b} .
$$

At prescribed $W, H, \theta_{b}, b$ and constant thermal properties, the optimum spacing between fins may be obtained by letting $d Q / d s=0$. It gives

$$
B_{i}+4 B_{i} \beta-\frac{4}{3}\left(2 B_{i}\right)^{1 / 2} \psi-4 B_{i} \beta \psi^{2}=0,
$$

where

$$
\psi=\frac{I_{2 / 3}\left[2\left(2 B_{i}\right)^{1 / 2} \beta\right]}{I_{-1 / 3}\left[2\left(2 B_{i}\right)^{1 / 2} \beta\right]} .
$$

Similarly, the optimum aspect ratio and heat transfer rate of this fin array are derived as

$$
\left(\frac{l}{b}\right)_{\text {opt }}=\frac{3 \beta}{2},
$$

and

$$
Q^{*}=\left\{(\not \beta-1)\left(\frac{B_{i}}{2}\right)^{1 / 2}+\psi\right\} /(\not \beta) .
$$

The fin efficiency of this fin becomes

$$
\eta=\frac{2 \psi}{3 \beta\left(2 B_{i}\right)^{1 / 2}}
$$

and overall surface efficiency is written as

$$
\epsilon=1-\frac{3 \beta(1-\eta)}{\beta(\gamma+3)-1}
$$

In the above equations, the definitions of $\gamma$ and $\beta$ are the same as those given in the previous case.

\section{Optimum Array with Triangular Fins $(n=1)$}

It is noted that the tip temperature of this fin must be finite. The heat dissipation of a triangular fin is obtained as [2]

$$
Q_{f}=\theta_{b} H(2 k b h)^{1 / 2} \frac{I_{1}\left[\left(\frac{2 h}{k b}\right)^{1 / 2} 2 l\right]}{I_{0}\left[\left(\frac{2 h}{k b}\right)^{1 / 2} 2 l\right]} .
$$

For this case, the heat duty of the fin array is written as

$$
Q=\frac{W H \theta_{b}}{b+s}\left\{h s+(2 k b h) \frac{I_{1}\left[\left(\frac{2 h}{k b}\right)^{1 / 2} \frac{4 V(b+s)}{W H b}\right]}{I_{0}\left[\left(\frac{2 h}{k b}\right)^{1 / 2} \frac{4 V(b+s)}{W H b}\right]}\right\}
$$

Similar to the procedures of previous cases, an optimum relationship is obtained as

$$
B_{i}+8 B_{i} \beta-2\left(2 B_{i}\right)^{1 / 2} \psi-8 B_{i} \beta \psi^{2}=0,
$$




$$
\psi=\frac{I_{1}\left[4\left(2 B_{i}\right)^{1 / 2} \beta\right]}{I_{0}\left[4\left(2 B_{i}\right)^{1 / 2} \beta\right]} .
$$

The optimum aspect ratio has the form:

$\left(\frac{l}{b}\right)_{o p t}=2 \beta$.

The formula of the maximum heat transfer rate of an array with triangular fins is identical to Eq. (17). The fin efficiency and overall surface efficiency are evaluated from

$$
\eta=\frac{\psi}{2 \beta\left(2 B_{i}\right)^{1 / 2}},
$$

and

$$
\epsilon=1-\frac{4 \beta(1-\eta)}{\beta(\gamma+4)-1} .
$$

\section{Optimum Array with Concave Parabolic Fins $(n=2)$}

This fin exists on the condition that the temperature at tip is the same as that of the environmental fluid. The heat transfer rate of this fin is given as [2]

$$
Q_{f}=\frac{\theta_{b} H k b}{2 l}\left[-1+\left(1+4 m^{2} l^{2}\right)^{1 / 2}\right],
$$

The total heat dissipation of the array is expressible as

$$
\begin{aligned}
Q & =\frac{W H \theta_{b}}{b+s}\left\{h s+\frac{W H b^{2} k}{6 V(b+s)}[-1\right. \\
& \left.\left.+\left(1+4 m^{2} l^{2}\right)^{1 / 2}\right]\right\},
\end{aligned}
$$

where

$$
m l=\left(\frac{2 h}{k b}\right)^{1 / 2} \frac{3 V(b+s)}{W h b} .
$$

Differentiating Eq. (28) relative to $s$ yields the optimum equation below:

$$
1+36 B_{i} \beta^{2}-\left(1+3 B_{i} \beta\right)\left(1+72 B_{i} \beta^{2}\right)^{1 / 2}=0
$$

The optimum aspect ratio is obtained from the solution of Eq. (30) for a given $B_{i}$ and is written as

$$
\left(\frac{l}{b}\right)_{\text {opt }}=3 \beta \text {. }
$$

The dimensionless heat transfer rate of the optimized fin array becomes

$$
\begin{aligned}
Q^{*} & =\left\{(\not \beta-1)\left(\frac{B_{i}}{2}\right)^{1 / 2}+\frac{-1+\left(1+72 B_{i} \beta^{2}\right)^{1 / 2}}{6\left(2 B_{i}\right)^{1 / 2} \beta}\right\} \\
& /(\not \beta) .
\end{aligned}
$$

In addition, the fin efficiency and overall sur- face efficiency becomes

$$
\eta=\frac{-1+\left(1+72 B_{i} \beta^{2}\right)^{1 / 2}}{36 B_{i} \beta^{2}}
$$

and

$$
\epsilon=1-\frac{6 \beta(1-\eta)}{\beta(\gamma+6)-1} .
$$

Note that the formulae of the optimum spacings of the arrays with rectangular, convex parabolic, triangular, and concave parabolic fins are all identical and can be calculated directly from Eq. (7)

\section{RESULTS AND DISCUSSION}

From the foregoing analysis, the optimum spacing of fin arrays can be obtained for a given geometry of the base plate, total fin volume and the transverse Biot number. Initially, to check the accuracy of the present model, a comparison in temperature profiles along the center line is made between the proposed solutions with two-dimensional ones. Figure 2 shows the error rate (the differences of the two temperatures divided by the temperature calculated from one-dimensional analysis) along the fin length. Note that the origin of the coordinate system is taken at fin tip and positive $x$ is toward the fin base. It is apparent that the deviation increases as $B_{i}$ increasing. Thus, it is recommended that $B_{i}$ should not be far greater than 0.01 for accuracy of the proposed model.

The dependence of optimum aspect ratio on $B_{i}$

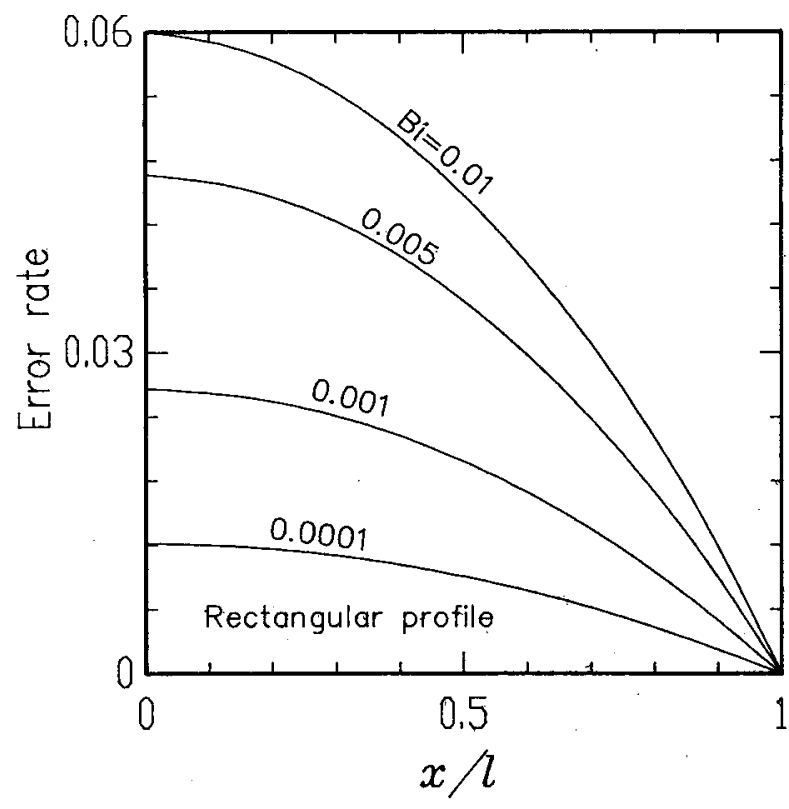

Fig. 2. Error rate of the temperature at center line of a rectangular fin. 
for single fins and fin arrays is illustrated in Fig. 3. For fin arrays, at a known $B_{i}$ the aspect ratios of fins from large to small are $n=0,0.5,1$, and 2 respectively. Special attention is given on that $(l / b)_{\text {opt }}$ of $n=0$ and 2 for single fins almost coincide. On the whole, the values of $(l / b)_{\text {opt }}$ is smaller for fin array than for single fins at a specified $B_{i}$. The dependence of $N b / W$ on $B_{i}$ are shown in Fig. 4. With known $b$ and $W$, the optimum number, $N$, of fins for fin arrays can be evaluated. It is observed that the optimum numbers of fins in arrays have an inverse effect to the aspect ratios. This is due to the fact that the present results are obtained at a given total fin volume, $V$, and a fin thickness at root. For a concaveparabolic-profile fin $(n=2)$, its value of $(l / b)_{\text {opt }}$ is the smallest, hence $N b / W$ is the largest. In addition, it is observed that the larger $\gamma(=W H b / V)$ is, the smaller the optimum number of fins is needed to achieve the maximum heat dissipation of a fin array. For clarity, only the cases of $\gamma=1.4$ and 1.7 are given in this figure.

The optimum spacing between fins in a fin array depends upon $n$ and $\gamma$. Figure 5 plots the dependence of the optimum spacing of fin arrays on $B_{i}$. For an optimized fin array, $(s / b)_{\text {opt }}$ is the smallest for a concave parabolic fin assembly whereas it is the largest for a rectangular fin array. Also, $(s / b)_{\text {opt }}$ increases with increasing $\gamma$. The maximum heat transfer rates from various optimized fin arrays are depicted in Fig. 6. It is shown that $Q^{*}$ is the largest for $n=2$ and is the smallest for $n=0$. This result is similar to the optimum numbers of fins in an array stated

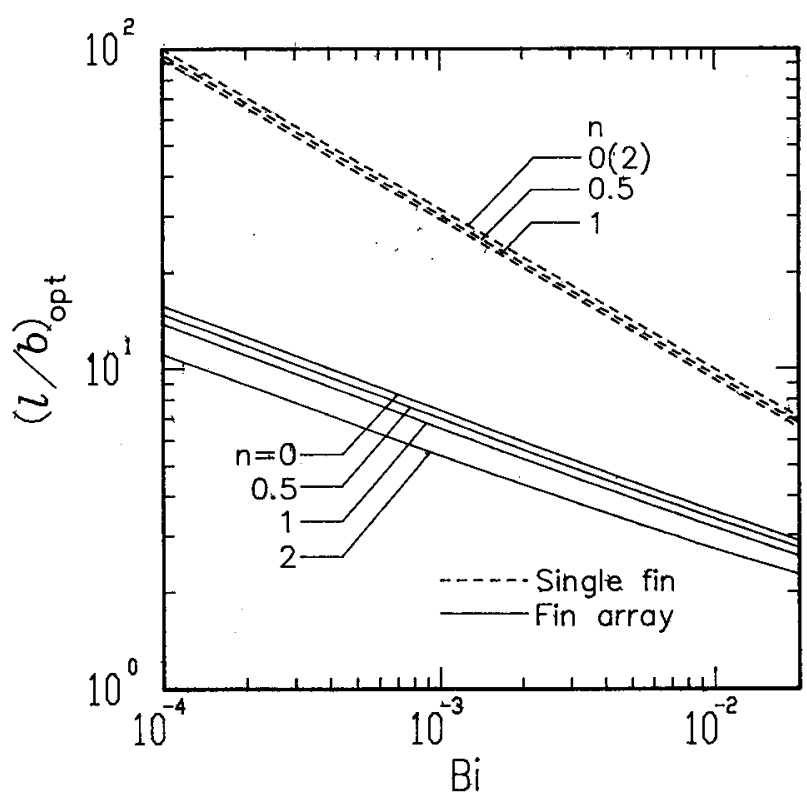

Fig. 3. Dependence of the optimum aspect ratio on $B_{i}$. previously. From the heat transfer point of view, it is preferred to have larger numbers of smaller fins than larger ones at a given total fin volume. In addition, the dimensionless maximum heat transfer rate decreases as $\gamma$ increases.

Figure 7 indicates the overall surface efficiencies of the optimized fin arrays for $n=0,0.5,1$, and 2 . It is shown that the present model predicts that the efficiencies of the optimum assemblies are all well above 0.85 in the valid range $\left(B_{i}<0.02\right)$. Apparently, the efficiencies of optimum arrays from large to small are rectangular, convex-parabolic, triangular, and concave-parabolic fin arrays respectively. Additionally, the overall surface efficiency is larger for a larger $\gamma$ at a given $B_{i}$.

\section{CONCLUSIONS}

In this study, the optimum spacings of longitudinal fin arrays are obtained at a given geometry of base plate, total fin volume, and transverse Biot number. Four longitudinal extended surfaces including rectangular, convex parabolic, triangular, and concave parabolic fins are considered. It is concluded that the optimum aspect ratio as well as spacing is the largest for a rectangular fin and smallest for a concave-parabolic-profile fin. The maximum total heat duty is the largest for a concaveparabolic-fin array and is the smallest for a rectangular-fin array. The overall surface efficiencies of the optimum fin assemblies from large to small are a rectangular-fin, a convex-parabolic-fin, a triangular-

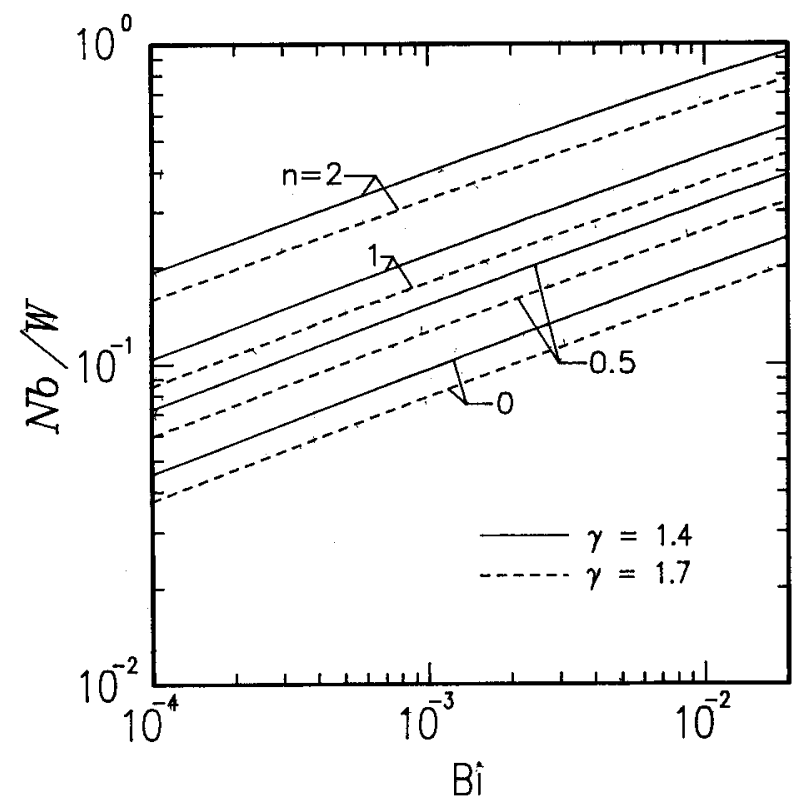

Fig. 4. Dependence of the optimum number of fins on $\boldsymbol{B}_{\boldsymbol{i}}$. 


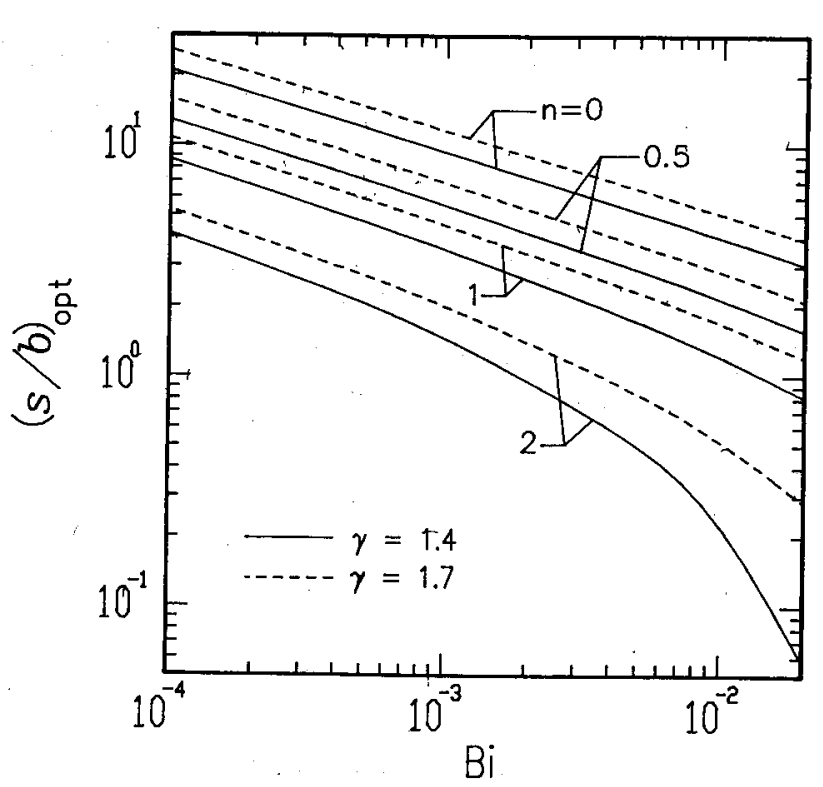

Fig. 5. Dependence of the optimum spacing of fin arrays on $B_{i}$.

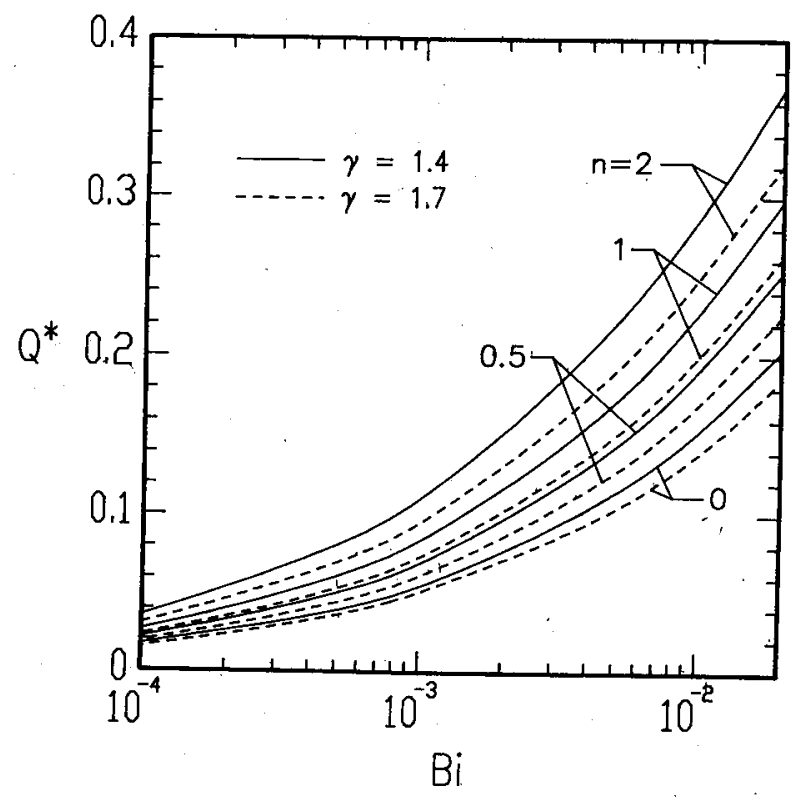

Fig. 6. Dependence of the maximum heat transfer rate on $B_{i}$.

fin, and a concave-parabolic-fin arrays respectively.

\section{NOMENCLATURE}

$B_{i} \quad$ Biot number, $h b / k$

$b$ fin thickness at fin base

$H$ fin width

$h \quad$ heat transfer coefficient

$k \quad$ thermal conductivity of the fin

fin height

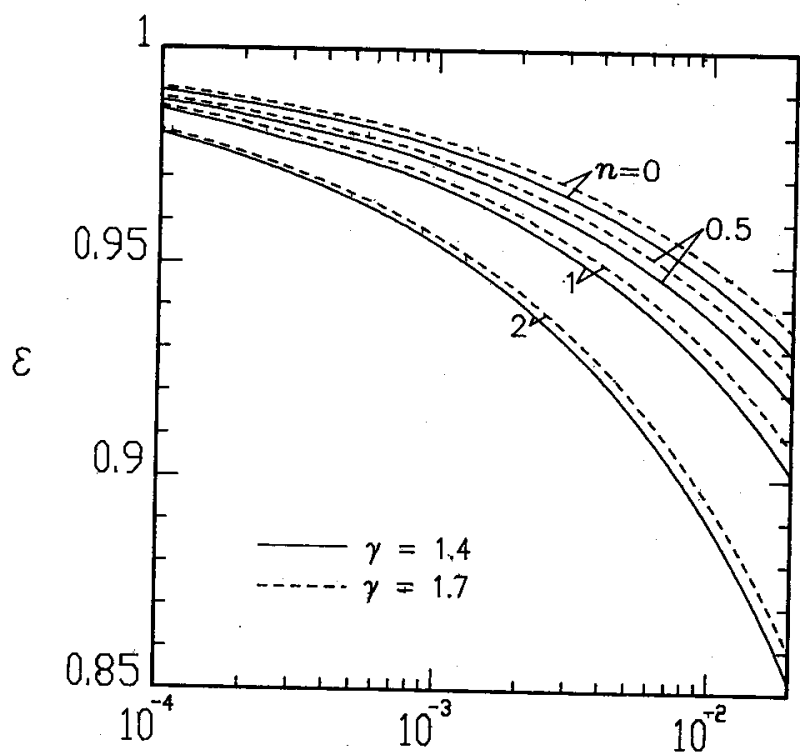

$\mathrm{Bi}$

Fig. 7. Overall surface efficiencies of optimum fin arrays.

$m$ parameter, Eq. (13)

$N$ number of fins, $W /(b+s)$

$n \quad$ profile index, Eq. (1)

$Q \quad$ heat transfer rate of array

$Q^{*} \quad$ dimensionless heat duty of array,

$\frac{Q}{W H \theta_{b}(2 k h / b)^{1 / 2}}$

fin spacing

total volume of fins

width of fin array

coordinate

\section{Greek Symbols}

$\beta$ dimensionless parameter, $V(b+s) /\left(W H b^{2}\right)$

$\gamma$ dimensionless parameter, $W H b / V$

$\eta \quad$ fin efficiency

$\psi \quad$ variable, Eqs. (15) and (23)

$\boldsymbol{\theta}$ temperature difference between fin surface and ambient fluid

$\epsilon \quad$ overall surface efficiency

\section{Subscripts, Superscripts}

$\begin{array}{ll}b & \text { fin base } \\ f & \text { single fin } \\ \text { opt } & \text { optimum } \\ * & \text { nondimensional quantity }\end{array}$

REFERENCES

1. Kraus, A.D., "Sixty-five Years of Extended Surface Technology (1992-1987),"Appl. Mech. Rev., Vol.41, 
pp. 321-364 (1988).

2. Kern, D.Q. and Kraus, A.D., Extended Surface Heat Transfer, McGraw Hill, New York, (1972).

3. Laor, K. and Kalman, H., "The Effect of Tip convection on the Performance and Optimum Dimensions of Cooling Fins," Int. Comm. Heat Mass Transfer, Vol. 19, pp. 569-584 (1992).

4. Sohrabpour, S. and Razani, A., "Optimization of Convective Fin with Temperature-Dependent Thermal Parameters," J. of the Franklin Institute, Vol. 330, pp. 37-49 (1993).

5. Chung, B.T.F. and Iyer, J.R., "Optimum Design of Longitudinal Rectangular Fins and Cylindrical Spines with Variable Heat Transfer Coefficient, Heat Transfer Engineering, Vol. 14, pp. 31-42 (1993).

6. Yeh, R.H. and Liaw, S.P., "Optimum Configuration of a Fin for Boiling Heat Transfer," $J$ of the Franklin Institute, Vol. 330, pp. 153-163 (1993).

7. Yeh, R.H., "Optimum Spines with Temperature Dependent Thermal Parameters," Int. J. Heat Mass Transfer, Vol. 37, pp. 1877-1884 (1994).

8. Starner, K.E. and McManus, H.N., "An Experimental Investigation of Free Convection Fin Arrays," J. Heat Transfer, Vol. 85, pp. 273-278.

9. Welling, J.R. and Wooldridge, C.B., "Free-Convection Heat-Transfer Coefficients from Rectangular Vertical Fins," J. Heat Transfer, Vol. 87, pp. 439-444 (1965).

10. Bar-Cohen, A., "Fin Thickness for An Optimized Natural-Convection Array of Rectangular Fins," $J$. Heat Transfer, Vol. 101, pp. 564-566 (1979).

11. Leung, C.W. and Probert, S.D., "Natural-Convective Heat Exchanger with Vertical Rectangular Fins and Base: Design Criteria," Proc. Instn. Mech. Engrs., Vol. 201, pp. 365-372 (1987).

12. Dhar, P.L. and Arora, C.P., "Optimum Design of Finned Surfaces," J. of the Franklin Institute, Vol. 301, pp. 379-392 (1976).

13. Bar-Cohen, A and Jelinek, M., "Optimum Arrays of
Longitudinal, Rectangular Fins in Convective Heat Transfer," Heat Transfer Engineering, Vol. 6, pp. 6878 (1985).

14. Gardner, K.A., "Efficiency of Extended Surfaces," Trans. ASME, Vol. 67, pp. 621-631 (1945).

15. Murray, W.M., "Fin analyses," J. Appl. Mech., Vol. 5, A78 (1938).

16. Incropera, F.P. and DeWitt, D.P., Introduction to Heat Transfer, 3rd ed., John Wiley \& Sons, New York, (1996).

\section{縱向数流鯺組之最佳鯺間距 葉 第 華}

海洋大學輪機工程技術系

$$
\text { 廖世平 }
$$

海洋大拿機械與輪機工程學系

張 明

\section{海洋大學航運技術研究所}

\section{摘 要}

本计書主要以理論來分析縱向散熟片組於強 制数流下之最佳間距。矩形、吕执物線、三角形以 及凹扰物線等四種形狀鯺皆運用於此散熱片組內。 在給予已知的基板幾何形状之大小、鯺總體積與横 向畢雨数，此最佳化散熟片組之鯺長高比、鯺間距 及鮽熱傅特性可分別-D求出。此外, 釬對此四種 不同的鯺組, 本研究還以同體積鯺的條件下, 作總 熟傅與鯺效率的比較。為了便於多数研究與設計分 析, 所有的研究結果均以與因次的形式來表示。 